\title{
The effects of the putative confession and evidence presentation on maltreated and non- maltreated 9- to 12-year-olds' disclosures of a minor transgression
}

\author{
Angela D. Evans ${ }^{a, *}$, Thomas D. Lyon ${ }^{b}$ \\ a Department of Psychology, Brock University, St. Catharines, Ontario L2S 3A1, Canada \\ ${ }^{\mathrm{b}}$ Gould School of Law, University of Southern California, Los Angeles, CA 90089, USA
}

\section{A R T I C L E I N F O}

\section{Article history:}

Received 27 September 2018

Revised 23 July 2019

Available online 30 August 2019

\section{Keywords:}

Disclosure

Honesty

Putative confession

Evidence presentation

Forensic interview

Child maltreatment

\begin{abstract}
A B S T R A C T
The current study examined the influence of the putative confession (in which children are told that the suspect told them "everything that happened" and "wants [the child] to tell the truth") and evidence presentation on 9- to 12-year-old maltreated and non-maltreated children's disclosure $(N=321)$. Half of the children played a forbidden game with an adult confederate that resulted in a laptop computer breaking (no transgression occurred for the other half of the children), followed by coaching to conceal the forbidden game and to falsely disclose the sanctioned game. Children were then interviewed about the interaction with the confederate. Among the 9- and 10-year-olds, the putative confession led to a higher rate of breakage disclosure (62\%) than the control condition (13\%) and to a higher rate of leakage of incriminating details during recall ( $47 \%$ vs. $9 \%$ ). Older children were more likely to disclose than younger children and to be uninfluenced by the putative confession. Among all ages, evidence presentation elicited disclosures from $63 \%$ of children who had not previously disclosed without eliciting any false disclosures.
\end{abstract}

(c) 2019 Elsevier Inc. All rights reserved.

\footnotetext{
* Corresponding author.

E-mail address: aevans@brocku.ca (A.D. Evans).
} 


\section{Introduction}

Obtaining honest and accurate reports is one of the most important tasks that forensic interviewers and legal professionals are charged with when interviewing potential witnesses and victims of an alleged crime. When children are interviewed, it is typically about the alleged wrongdoing of an adult, often actions in which the children feel implicated. For example, children are most often called to testify in child sexual abuse prosecutions (Goodman, Quas, Bulkley, \& Shapiro, 1999), and sexually abused children frequently exhibit self-blame (Quas, Goodman, \& Jones, 2003). Feelings of shame, guilt, or fear often result in reluctance to disclose (Anderson, Martin, Mullen, Romans, \& Herbison, 1993). Thus, it is imperative to develop methods that assist in increasing children's honest and accurate disclosures of their own and others' transgressions.

The developmental literature on children's ability to conceal wrongdoings suggests that children are able to tell lies as early as 2 or 3 years of age (Evans \& Lee, 2013; Williams, Leduc, Crossman, \& Talwar, 2017; Wilson, Smith, \& Ross, 2003). By 4 years of age, the majority of children will deny their own transgressions (e.g., Polak \& Harris, 1999; Talwar \& Lee, 2002) and conceal transgressions in which they are implicated (Lyon et al., 2014; Lyon, Malloy, Quas, \& Talwar, 2008; Rush, Stolzenberg, Quas, \& Lyon, 2017). Throughout childhood, the sophistication of children's ability to tell lies increases (Evans, Xu, \& Lee, 2011; Gervais, Tremblay, Desmarais-Gervais, \& Vitaro, 2000; Talwar \& Lee, 2002, 2008; Wilson et al., 2003), with children's ability to maintain their lies across questions and avoid leaking incriminating details (known as semantic leakage control; Talwar \& Lee, 2002) increasing with age. Studies suggest that during late childhood lie-telling rates may decline in frequency (Evans \& Lee, 2011; Pipe \& Wilson, 1994), although more than 50\% of 11- to 13-year-olds will still lie to conceal a transgression (Evans \& Lee, 2011). Given the increased ability to maintain lies and relatively high rates of lie-telling during middle to late childhood, it is important to find techniques for promoting honesty and increasing disclosure rates.

\section{Truth induction}

To date, several studies have examined various techniques for increasing children's disclosures of a transgression, including recognition questions that explicitly mention the transgression, reassurance, external appeals for honesty, and promising to tell the truth. The use of yes/no recognition questions has been found to increase disclosures, but it has also been found to elicit some false reports (Ahern, Stolzenberg, McWilliams, \& Lyon, 2016). Reassuring children that telling about what happened will not result in negative consequences has also been found to increase children's disclosure rates (Lyon \& Dorado, 2008; Lyon et al., 2008, 2014); however, it can be suggestive and cannot be used in many cases because the interviewer often cannot make such a guarantee. In addition, external appeals for honesty (Talwar, Arruda, \& Yachison, 2015), in which the interviewer tells the child that the interviewer will be happy if the child tells the truth, have been found to be an effective technique for increasing honesty.

Perhaps the most effective tool with extensive empirical support is promising to tell the truth. A number of studies have confirmed positive effects, with no evidence that it increases false reports (e.g., Evans \& Lee, 2010; Lyon \& Dorado, 2008; Lyon et al., 2008; Talwar \& Lee, 2002). However, dishonesty rates still remain high, particularly among older children and adolescents between 8 and 16 years of age (Evans \& Lee, 2010), and the efficacy of the promise in eliciting disclosures of transgressions is limited with younger children (Bender, O'Connor, \& Evans, 2018; Quas, Stolzenberg, \& Lyon, 2018). Moreover, recent evidence suggests that the promise has limited utility in eliciting disclosures from maltreated children when only recall questions are asked (McWilliams, Stolzenberg, Williams, \& Lyon, n.d.).

\section{The putative confession}

A promising alternative to the above techniques is the putative confession, in which the interviewer tells the child that the suspect "told me everything that happened" and "wants [the child] 
to tell the truth." The putative confession may be motivating for children who have concerns about the perpetrator's reaction to disclosure. By explaining that the perpetrator already disclosed what has happened and wants the child to tell the truth, children's fears about disclosing and the pressure to be the first to disclose may be reduced. This approach has been found to increase honesty about a transgression (e.g., breaking toys when playing with a stranger) in response to recall questions among children 4 to 9 years of age, with no differences in efficacy across age (Lyon et al., 2014; McWilliams, Stolzenberg, Williams, \& Lyon, n.d.; Quas, Stolzenberg, \& Lyon, 2018; Rush, Stolzenberg, Quas, \& Lyon, 2017; Stolzenberg, McWilliams, \& Lyon, 2017).

Although the interviewer claims to know what occurred, which risks suggestion, the interviewer does not specify what the suspect said, emphasizing that the suspect wants the child to be truthful. If a transgression did occur, the child can readily infer that the perpetrator disclosed the transgression. However, if no transgression occurred, the child can simply interpret the statement as the accused disclosed the truth that nothing happened. Rush et al. (2017) demonstrated that the putative confession was effective even after children were suggestively questioned by a parent, both increasing disclosure of breakage and reducing false reports (falsely reporting having played with toys they did not play with). Questioning children after a delay, Cleveland, Quas, and Lyon (2018) found that the putative confession combined with suggestive questioning did not increase false reports.

\section{Omission and commission coaching}

One aspect of the child-perpetrator interaction that may influence the effectiveness of the putative confession is coaching. Coaching has been defined as "efforts by instigators to encourage and rehearse dishonesty in children" (Lyon et al., 2008). Concerns of coaching often occur in maltreatment cases; the defense often argues that children were coached to make a false allegation (Brennan, 1994), whereas the prosecution argues that inconsistencies in a child's statement result from coaching by the accused (Summit, 1983). One can distinguish between two types of coaching: omission coaching, in which the child is coached on what not to say and what to deny, and commission coaching, in which the child is coached to provide false information. Previous studies examining adult influences on children's disclosure have typically focused on omission coaching. For example, in many studies, confederates simply asked the child to keep the transgression a secret and neither rehearsed questions nor provided a false story (e.g., Pipe \& Wilson, 1994). Some studies have gone a bit further and practiced questions with children as well as urged children to claim that the only thing they did was engage in one of the innocuous activities (Lyon et al., 2008; Talwar, Yachison, Leduc, \& Nagar, 2018).

A relatively small number of studies have examined commission coaching, in which the child is encouraged to falsify information. Tye, Amato, Honts, Devitt, and Peters (1999) demonstrated that a majority (56\%) of 6- to 10-year-olds who witnessed a parent steal a book falsely accused a research assistant of stealing the book after their parent encouraged them to do so. Lyon and colleagues (2008) demonstrated that $82 \%$ of maltreated 4 - to 9-year-olds falsely recalled that they played with toys after receiving commission coaching. Fogliati and Bussey (2015) found that $80 \%$ of 6 - to 8year-olds could be coached to falsely recall that a teacher had ripped a poster.

Commission coaching is particularly important to understand in relation to the putative confession because commission coaching may influence children's interpretation of what the suspect told the interviewer. It is possible that such coaching results in children interpreting "everything that happened" as the false story they were coached to report and, thus, may undermine the efficacy of the putative confession. This may be particularly important with older children, who could see through the ambiguity of the statement "everything that happened."

\section{Leakage}

Leakage refers to the inadvertent disclosure of details that one is inclined to conceal. Previous studies examining leakage among children used a paradigm in which children's ability to guess the identity of a toy implied that the children must have peeked at the toy because simply hearing the toy would be uninformative. To avoid leakage, children needed to refrain from guessing, recognizing that the interviewer could infer that they must have peeked, which requires theory of mind skills (Evans \& 
Lee, 2011; Talwar \& Lee, 2002, 2008; Talwar, Gordon, \& Lee, 2007; Williams, Moore, Crossman, \& Talwar, 2016). A simpler form of leakage occurs when one discloses details of a transgression one intended to conceal. This implicates source monitoring (one must distinguish between transgressive and non-transgressive behaviors) and is analogous to the "guilty knowledge" test for detecting deception, in which guilty suspects exhibit arousal to details that only the guilty would know (e.g., BenShakhar \& Elaad, 2003).

Even if truth induction methods do not induce honesty, they may increase leakage. Leach, Talwar, Lee, Bala, and Lindsay (2004) found that adults were better able to distinguish between honest and dishonest children when children had completed a moral reasoning task or had promised to tell the truth. The authors proposed that increasing the salience of honesty may have interfered with children's ability to regulate their behavior, making their dishonesty more easily detected. We suspected that the putative confession might impair children's ability to selectively report details of the game they were coached to report and to omit details of the game they were coached to deny.

\section{Evidence presentation}

Presenting evidence during forensic interviews is often recommended in interviewing protocols for those children who have failed to disclose to initial questions (American Professional Society on the Abuse of Children, 2012; Connell \& Finnegan, 2010; National Children's Advocacy Center, 2013; State of Michigan Governor's Task Force on Child Abuse and Neglect and Department of Health and Human Services, 2015). Although children are often the only witnesses to their abuse, an increasing number of child sexual abuse cases began with interactions over the internet (Kloess, Beech, \& Harkins, 2014), and there is often evidence of these interactions (Katz, Piller, Glucklich, \& Matty, n. d.). However, no research has examined the influence of presenting evidence on children's disclosures, and it is important to consider whether it increases false allegations (Lytle, Dickinson, \& Poole, 2019).

\section{Maltreatment differences}

Research examining children's transgressions has sometimes revealed greater reluctance among maltreated children to disclose. Talwar and Lee (2011) found that 3- and 4-year-olds in a physically punitive school environment were significantly less likely to acknowledge peeking at a toy (after being admonished not to peek) compared with children in a school that did not use corporal punishment. McWilliams, Stolzenberg, Williams, \& Lyon, n.d. found that maltreated 4- to 9-year-olds were less likely than non-maltreated children to disclose having broken toys while playing with a stranger (and being admonished not to tell), whereas earlier studies did not report any differences (Lyon et al., 2014; Stolzenberg et al., 2017) or noted nonsignificant tendencies toward less disclosure among maltreated children (Ahern et al., 2016; Quas et al., 2018).

\section{The current study}

The current study examined the influence of the putative confession and evidence presentation on 9- to 12-year-old maltreated and non-maltreated children's coached reports of a minor transgression. Children played with a confederate on a computer. Half of the children were randomly assigned to the Break condition, in which the game appeared to cause the computer to crash and the confederate confessed that they were not supposed to play the game. This interaction mimics an abuse situation where the child is convinced by an adult to engage in an activity that the child does not initially understand is wrong. The confederate coached children in the Break condition to conceal 4 Played Game details (omission coaching) and falsely report 4 Not-Played Game details (commission coaching). The other half of the children were assigned to the No-Break condition in which no transgression occurred.

Children were then interviewed in either the Putative Confession or Control interview condition. The interview included open-ended recall questions followed by 20 yes/no recognition questions ( 8 inquired into Played Game details, 8 inquired into Not-Played Game details, and 4 inquired into details 
that did not appear in either game [Non-occurring Game]), a mid-interview pause, and finally presentation of evidence that the transgression occurred (the error message on the computer screen).

We predicted that, consistent with prior research, older children would be more likely to disclose the transgression than younger children and that the putative confession would increase disclosures (without increasing false disclosures) among all children. However, we anticipated that the putative confession might be less effective for older children, who could see through the ambiguity of "told me everything that happened" or interpret it as referring to the coached false report. We anticipated that omission and commission coaching would enable children to avoid disclosing the details of the game they played and falsely disclose details of the game they did not play, although we predicted that the putative confession would lead to increased leakage of details about the played game. We predicted that the presentation of evidence of the transgression would result in additional true disclosures without an increase in false disclosures. Finally, we assessed whether maltreated children were less likely than non-maltreated children to disclose breakage.

\section{Method}

\section{Participants}

A total of 3219 - to 12 -year-old children ( $M=10.50$ years, $S D=1.12 ; 153$ boys $)$ participated in this study. Approximately half of the children were maltreated $(n=161$; this included 809 - and 10 -yearolds $[M=9.50$ years, $S D=0.50 ; 38$ boys $]$ and 8111 - and 12 -year-olds $[M=11.51$ years, $S D=0.50 ; 41$ boys]).

The maltreated sample consisted of children from the Los Angeles County dependency court who had been removed from the custody of their parents or guardians for substantiated cases of abuse or neglect. Because children had been removed from parental care, the Presiding Judge of Juvenile Court granted consent for all children in the maltreated sample. Maltreated children were ineligible if they were awaiting adjudication or contested disposition hearing on the date of testing (because they might be asked to testify) or if interpreter services were provided to their family and they were incapable of communicating with the researchers in English. Children were primarily from ethnic/racial minority backgrounds: 56\% Latino, 28\% African American, 8\% Caucasian, and 8\% other.

The non-maltreated sample consisted of 160 children (this included 80 9- and 10-year-olds $[M=9.50$ years, $S D=0.50 ; 39$ boys $]$ and 8010 - and 11 -year-olds $[M=11.51$ years, $S D=0.50 ; 35$ boys) recruited from schools in nearby predominantly low-income ethnic minority neighborhoods. Children were primarily from ethnic/racial minority backgrounds comparable to the maltreated sample: $54 \%$ Latino, 41\% African American, 2\% Caucasian, and 3\% other. Written consent was obtained from all non-maltreated children's parents prior to participating. All study procedures were approved by the University of Southern California institutional review board.

\section{Procedure}

\section{Transgression paradigm}

All children were invited to participate in the study, and their assent was obtained prior to commencing. The session began with the child completing several tasks, unrelated to the current investigation, with a female interviewer for approximately $10 \mathrm{~min}$. On completion of the tasks, a male confederate entered the room and said that they were there to complete the video game activity. The female interviewer introduced the child to the confederate and excused herself from the room to complete some other work. She explained that when she returned she would ask the child some questions about the game played with the confederate. The confederate then opened a laptop computer and oriented the child to the two possible games: the Ball game and the Jewel game.

All children were assigned to one of two transgression conditions: Break or No-Break. In the Break condition, the confederate told the child that they were supposed to play one game but that he had played that game so many times he wanted to play the other game instead. The game played (Ball or Jewel) was counterbalanced between participants to ensure that interviewers were blind to the 
game the child had played and to control for possible differences in memorability or plausibility of game details. While playing the game, the confederate pointed out 8 target details (e.g., "Check out the birds") to ensure that the child noticed each of the details he or she would later be questioned about. After playing the game for $2 \mathrm{~min}$, the confederate instructed the child to click on a square that, unbeknownst to the child, was programmed to cause the computer to appear to crash (a blue error screen appeared). The confederate then confessed to the child that he forgot that they were not supposed to play that game because it crashes the computer and all the data were now lost. The confederate then told the child that the lady (the female interviewer), who was his boss, would be coming back in to ask the child about the game. The confederate asked the child not to tell the lady that they played that game, coached the child to conceal 4 of the target details (omission coaching; e.g., "Don't say that there were birds"), asked the child to falsify 4 details about the game they were supposed to have played (commission coaching; e.g., "Say you saw blocks falling"), and then put the computer away.

In the No-Break condition, the child played the appropriate video game (Ball or Jewel, counterbalanced between participants) and the game did not crash. While playing the game, the confederate pointed out the same 8 target details as in the Break condition. After playing the game, the confederate put the computer away and told the child that the lady, who was his boss, would be coming in to ask the child about the game and thanked the child for playing with him.

\section{Interview}

The rapport and recall phases of the interview were based on the National Institute of Child Health and Human Development (NICHD) Protocol, an international evidence-based investigative interviewing strategy for children (Lamb, Orbach, Hershkowitz, Esplin, \& Horowitz, 2007). The recall phase was then followed by a series of yes/no recognition questions and the presentation of evidence. Each phase of the interview is described in detail below.

Rapport phase. The same female interviewer from the start of the session then reentered the room. The interview began with a rapport phase in which the child was asked to talk about the last time he or she felt really good or bad at school. The interviewer asked the child to tell everything that happened from the very beginning to the very end. The interviewer used facilitators (e.g., "uh-huh") until the child completed his or her initial narrative and then followed up with "You said [action/verb the child reported]. Tell me more about [action/verb the child reported]." The rapport phase lasted for 2 min.

Recall phase. All children were assigned to one of two instruction conditions: Control or Putative Confession. Children in each instruction condition were matched for age and transgression condition (Break or No-Break). Children in the Control condition received the following instruction: "Now that I know you a little better, [child's name], tell me everything that happened while I was out of the room from the very beginning to the very end." Children in the Putative Confession condition were told, "Now that I know you a little better, [child's name], let me tell you something. The man, [confederate's name], who came in here, told me everything that happened and he said he wants you to tell the truth. Tell me everything that happened while I was out of the room from the very beginning to the very end." The interviewer used facilitators until the child completed his or her initial narrative. The child was asked to narrate the "first thing that happened," followed by a series of "what happened next" prompts until the child exhausted his or her narrative. On average, children were asked 2.75 "what happened next" prompts $(S D=2.35)$. The interviewer then used two follow-up open-ended prompts (e.g., "You said [action/verb]. Tell me more about [action/verb]."). For the two follow-up openended prompts, if the child mentioned the computer, the interviewer followed up on any action/verbs that were related to the computer. If the child did not say anything about the computer, the interviewer followed up on an action/verb central to the child's report. Finally, the child was asked to tell the interviewer everything the child heard ("Tell me everything you heard while I was gone") and everything the child saw ("Tell me everything you saw on the computer while I was gone").

Yes/No recognition questioning. Children were asked 20 yes/no recognition questions about the target items from the games (e.g., "Did birds fly across the screen?"; see Appendix for a full list of questions). 
Of these, 8 Played Game questions were from the game they played, 8 Not-Played Game questions were about the game they did not play, and 4 Non-occurring Game questions were about items that did not occur in either game (e.g., "Was there a dog in the video game?"). For children in the Break condition, 4 Played Game questions were items they were coached to conceal and 4 Not-Played Game questions were items they were coached to falsify.

Mid-interview pause. After completing the closed-ended questions, in an attempt to see whether nondisclosers would decide to disclose if given a moment alone to reflect, the interviewer said, "Now, I want to make sure I understood everything and see if there is anything else I want to ask. I will just go over my notes outside and come back in. Think about if there is anything else you want to tell me." The interviewer then exited the room for $2 \mathrm{~min}$. When the interviewer returned, she said to the child, "Okay. Hi, [child's name]. Did you think of anything while I was gone?" She used facilitators until the child completed any additional narrative.

Evidence presentation. The interviewer then presented the child with the blue error screen on the laptop. Because children in the No-Break condition did not break the computer, as the confederate left the room he inconspicuously set up the laptop to present the same blue screen with an error message as in the Break condition when the interviewer opened the laptop. This kept the interviewer blind to the child's condition and allowed for assessing whether evidence presentation would elicit false reports. The interviewer stated, "Okay, I am just going to look at the activity you did while I was gone on my computer" and opened the laptop to reveal the blue error screen. The interviewer then asked the child "What happened?" followed by "Tell me more about that" in response to any statement the child made. See Fig. 1 for the order of the procedure and Table 1 for the participant distribution across conditions.

Debriefing. All children were fully debriefed about the nature of the study. The confederate also told all children that it was his fault that the computer crashed and that it could be fixed. Children in all conditions were thanked for their time and for helping the experimenters learn about how to talk to children and were asked whether they had any questions. Finally, all children selected a small toy for participating in the study.

\section{Coding}

Research assistants transcribed and coded all transcripts for whether children disclosed the transgression. Any mention of the computer crashing, breaking, or freezing, a blue screen, or reference to having played a forbidden game was coded as a disclosure $(0=$ no disclosure, $1=$ disclosure $)$, and when the child disclosed during the interview was also recorded (rapport, recall, yes/no recognition questions, after the mid-interview pause, or after evidence presentation). We also coded for the number of target details children reported about the game they played and the number of target details they reported about the game they did not play (excluding duplicate details) during recall. For children in the Break condition, a dichotomous leakage variable was created such that $0=$ no leakage of details from the game played and 1 = leakage of game played (e.g., reporting any target details about the forbidden game). Interrater reliability was calculated on $10 \%$ of the data with kappas of 1.00 for the disclosure and leakage variables.

Finally, the child's responses to the yes/no questions were coded for whether the child provided an affirmative response ("yes" or nonverbal nod). Five yes/no question scores were created: played game coached (mean number of affirmative responses to questions about the game they played and were coached to deny), played game not coached (mean number of affirmative responses to questions about the game they played and were not coached about), not-played game coached (mean number of affirmative responses to questions about the game they did not play but were coached to report), notplayed game not coached (mean number of affirmative responses to questions about the game they did not play and were not coached about), and non-occurring (mean number of affirmative responses to questions about items that did not occur in either game). Although children in the No-Break condition were not coached, scores were created to match the question items in each of these categories 


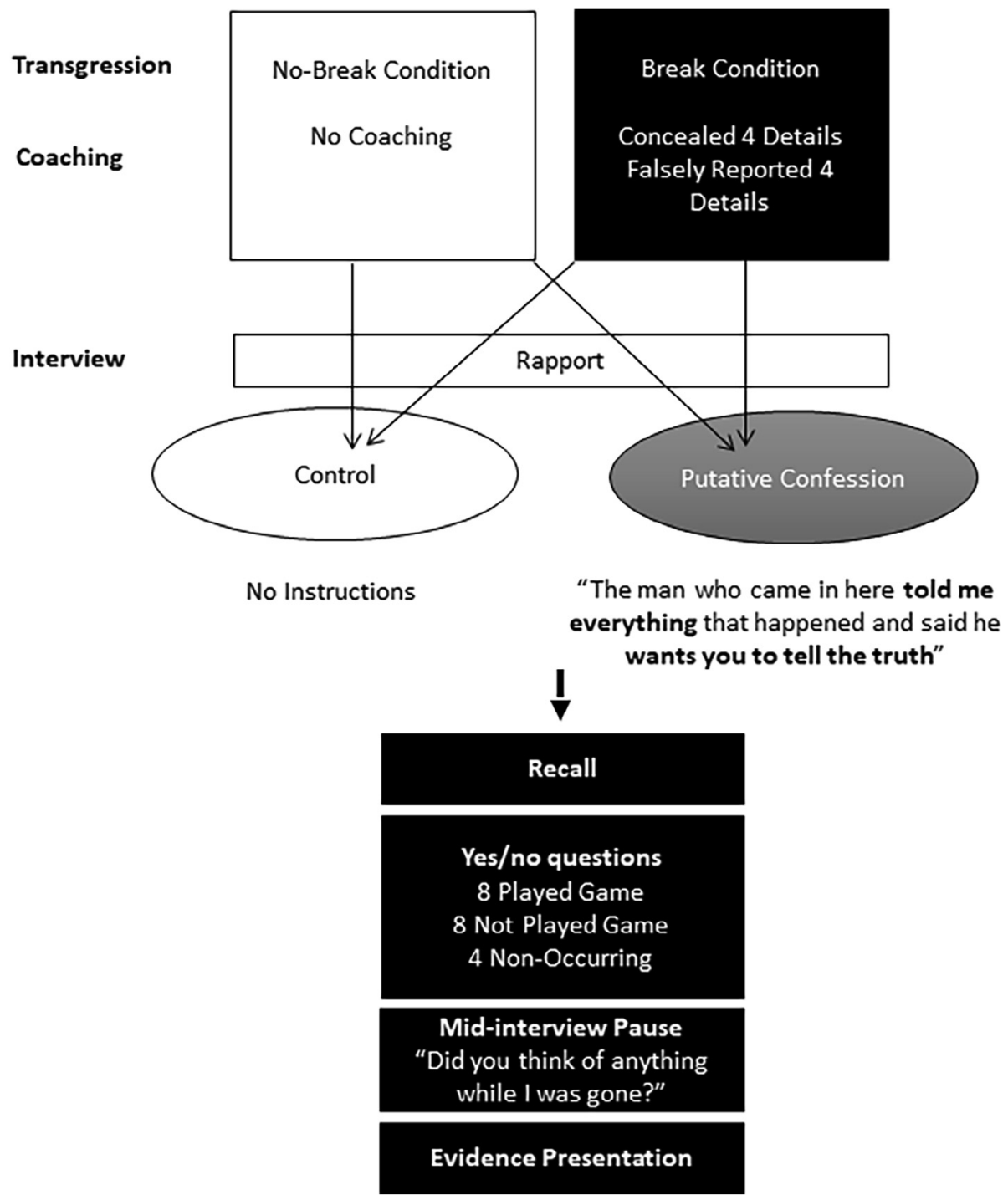

Fig. 1. Procedure diagram.

(e.g., a played game coached score was created using the same question items that were coached in the Break condition to control for any item-specific response patterns). Interrater reliability was calculated on $10 \%$ of the data for each of the yes/no questions, with kappas greater than .93 for all questions with the exception of three questions (one from the Jewel game, one from the Ball game, and one from neither game) with kappas greater than .85. All discrepancies were discussed and resolved between raters.

\section{Results}

We first examined whether children disclosed breakage and what factors influenced disclosure. Next, we examined the details reported by concealers (children who concealed the transgression in 
Table 1

Mean ages (and standard deviations) in years and $n s$ by age group, transgression condition, instruction condition, and maltreatment status.

\begin{tabular}{|c|c|c|c|c|c|}
\hline Age group & Transgression & Instruction & Maltreated & Non-maltreated & Total \\
\hline \multirow[t]{4}{*}{9 - and 10-year-olds } & \multirow[t]{2}{*}{ No-Break } & Control & $\begin{array}{l}M=9.45(0.51) \\
n=20\end{array}$ & $\begin{array}{l}M=9.45(0.51) \\
n=22\end{array}$ & 42 \\
\hline & & Putative Confession & $\begin{array}{l}M=9.50(0.51) \\
n=20\end{array}$ & $\begin{array}{l}M=9.50(0.51) \\
n=20\end{array}$ & 40 \\
\hline & \multirow[t]{2}{*}{ Break } & Control & $\begin{array}{l}M=9.50(0.51) \\
n=20\end{array}$ & $\begin{array}{l}M=9.58(0.51) \\
n=19\end{array}$ & 39 \\
\hline & & Putative Confession & $\begin{array}{l}M=9.55(0.51) \\
n=20\end{array}$ & $\begin{array}{l}M=9.47(0.51) \\
n=19\end{array}$ & 39 \\
\hline \multirow[t]{4}{*}{ 11- and 12-year-olds } & \multirow[t]{2}{*}{ No-Break } & Control & $\begin{array}{l}M=11.55(0.51) \\
n=20\end{array}$ & $\begin{array}{l}M=11.50(0.51) \\
n=20\end{array}$ & 40 \\
\hline & & Putative Confession & $\begin{array}{l}M=11.52(0.51) \\
n=21\end{array}$ & $\begin{array}{l}M=11.48(0.51) \\
n=21\end{array}$ & 42 \\
\hline & \multirow[t]{2}{*}{ Break } & Control & $\begin{array}{l}M=11.50(0.51) \\
n=20\end{array}$ & $\begin{array}{l}M=11.55(0.51) \\
n=20\end{array}$ & 40 \\
\hline & & Putative Confession & $\begin{array}{l}M=11.45(0.51) \\
n=20\end{array}$ & $\begin{array}{l}M=11.53(0.51) \\
n=19\end{array}$ & 39 \\
\hline Total & & & 161 & 160 & 321 \\
\hline
\end{tabular}

the Break condition) compared with truthful deniers (children in the No-Break condition) in response to the recall and yes/no recognition questions.

Children in the Break condition were asked more "what happened next" prompts during recall $(M=3.03, S D=1.88)$ than children in the No-Break condition $(M=2.47, S D=1.84), F(1,289)=4.67$, $p=.032$; thus, the number of prompts was included in the preliminary analyses but did not influence any of the results. Furthermore, preliminary analyses found no differences due to maltreatment, ethnicity, or gender. Thus, these variables were excluded from all reported analyses.

\section{Disclosure}

No children in the No-Break condition falsely disclosed that the computer had broken. Thus, the following disclosure analyses focus on children in the Break condition ( $n=157)$. Overall, 80\% ( $n=126 / 157$ ) of children in the Break condition disclosed prior to debriefing ( 1 during rapport, 72 during recall, none during the yes/no recognition questions, 1 after the mid-interview pause, and 52 after evidence presentation). Thus, $20 \%$ of children in the Break condition remained concealers across all phases of the interview.

We began by examining the rate of disclosures during recall by instruction condition, excluding the child who disclosed during rapport and, therefore, had disclosed before instructions (Fig. 1). Overall, $46 \%(n=72 / 156)$ of children disclosed during recall. A binary logistic regression was performed with disclosure of breakage during recall as the predicted variable and age group (9- and 10-year-olds or 11- and 12-year-olds), instruction condition (Control or Putative Confession), and the Age $\times$ Instruction condition interaction as the predictors. The model was significant, $\chi^{2}(3,156)=27.41, p<.001$, Nagelkerke $R^{2}=.214$. Only the Age $\times$ Instruction condition interaction significantly contributed above and beyond the common contribution of all other variables in the model, $B=1.82$, Wald(1) $=6.04 p=.014$, odds ratio $=6.13$.

Follow-up Pearson chi-square analyses comparing potential condition differences for each age group revealed that 9 - and 10-year-olds were significantly more likely to disclose the transgression in the Putative Confession condition (62\%) compared with the Control condition $(13 \%), \chi^{2}(1,78)$ $=21.10, p<.001$, Cramer's $V=.622$, whereas there were no significant condition differences among the 11 - and 12-year-olds, $\chi^{2}(1,78)=1.58, p=.210$, Cramer's $V=.179$ (63\% disclosure in the Putative Confession condition vs. $48 \%$ in the Control condition). In addition, follow-up Pearson chi-square analyses comparing potential age differences for each condition revealed a significant age difference in the 
Control condition, $\chi^{2}(1,79)=11.23, p=.001$, Cramer's $V=.41$, indicating that the 11 - and 12 -year-olds were significantly more likely to disclose in the Control condition (48\%) compared with the 9- and 10year-olds (13\%). However, there was no significant age difference in the rate of disclosure in the Putative Confession condition, $\chi^{2}(1,77)=0.021, p=.88$, Cramer's $V=.073$ (see Fig. 2).

Next, we examined children's disclosure rates in response to evidence presentation. Overall, $63 \%$ ( $n=52$ ) of the children who failed to disclose after both recall and yes/no questions $(n=83)$ disclosed in response to being shown the broken computer, and no child falsely acknowledged breakage in the No-Break condition. First disclosure during the evidence presentation $(0=$ no disclosure, $1=$ disclosure of breaking the computer) was entered as the predicted variable, and age group (9- and 10-year-olds or 11- and 12-year-olds), instruction condition (Putative Confession or Control), and the Age $\times$ Instruction condition interaction were entered as predictors. The model was not significant, $\chi^{2}(3,83)$ $=4.09, p=.251$, Nagelkerke $R^{2}=.065$. Hence, regardless of whether children had heard the putative confession, they were equally likely to confess when presented with evidence and were not inclined to falsely confess.

\section{Comparing concealers and truthful deniers}

\section{Reporting of Played Game details in recall}

We first examined whether concealers during recall in the Break condition $(n=84)$ reported significantly fewer Played Game details compared with children in the No-Break condition $(n=164)$. A 2 (Transgression Condition: Break or No-Break) $\times 2$ (Age Group: 9- and 10-year-olds or 11- and 12year-olds) $\times 2$ (Instruction Condition: Putative Confession or Control) univariate analysis of variance (ANOVA) was performed with transgression condition, age group, and instruction condition as the between-participant factors and the number of Played Game details that were reported as the dependent variable. There was a significant main effect of transgression condition, $F(1,240)=312.56$, $p<.001, \eta_{\mathrm{p}}^{2}=.57$, with children in the Break condition reporting significantly fewer Played Game details $(M=0.66, S D=1.35,8 \%)$ compared with children in the No-Break condition $(M=6.64$, $S D=2.82,83 \%$ ). No other main effects or interactions were significant.

\section{Reporting of not-played game details in recall}

Next, we examined whether concealers during recall in the Break condition $(n=84)$ reported significantly more details about the game they did not play (Not-Played Game details) compared with children in the No-Break condition $(n=164)$. A 2 (Transgression Condition: Break or No-Break) $\times 2$ (Age Group: 9- and 10-year-olds or 11- and 12-year-olds) $\times 2$ (Instruction Condition: Putative Confession or Control) univariate analysis of covariance (ANCOVA) was performed with transgression condi-

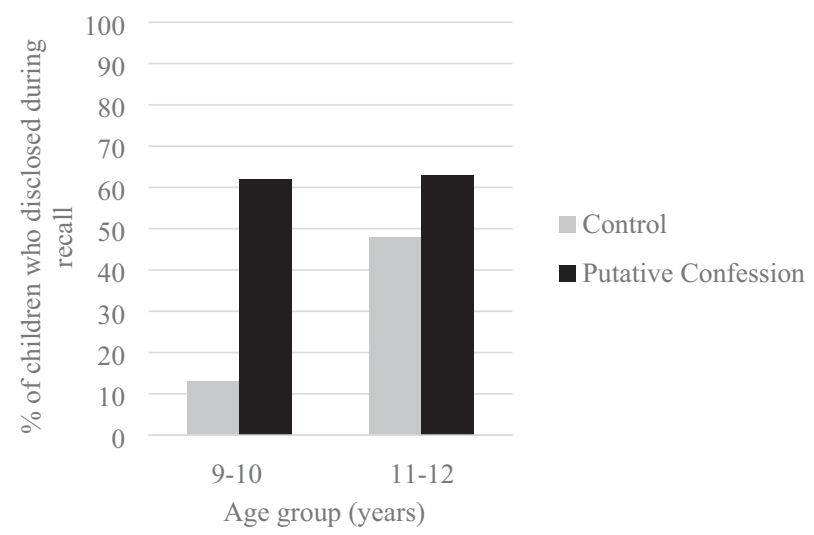

Fig. 2. Percentages of children in the Break condition $(n=156)$ who first disclosed during the recall phase of the interview by instruction condition and age group. 
tion, age group, and instruction condition as between-participant factors and the number of NotPlayed Game details that were reported as the dependent variable, covarying the total number of follow-up prompts. Again, a significant main effect of transgression condition was found, $F(1,240)$ $=573.74, p<.001, \eta_{\mathrm{p}}^{2}=.71$, with concealers in the Break condition reporting significantly more NotPlayed Game details $(M=6.13, S D=3.06,38 \%)$ compared with children in the No-Break condition, who almost never reported Not-Played Game details $(M=0.02, S D=0.14)$. In fact, only 3 children (2\%) in the No-Break condition reported a detail that was considered a Not-Played Game detail.

\section{Leakage of Played Game details during recall}

A logistic regression was performed on whether concealers $(n=84)$ leaked information about the forbidden game during recall $(0=$ no leakage, $1=$ leakage $)$ with age group ( 9 - and 10-year-olds or 11- and 12-year-olds), instruction condition (Putative Confession or Control), and an Age Group $\times$ Instruction Condition interaction entered as predictors. The model was significant, $\chi^{2}(3$, $84)=8.37, p=.039$, Nagelkerke $R^{2}=.148$, with instruction condition, $B=2.17$, Wald $(1)=7.42$, $p=.006$, and the Age Group $\times$ Instruction Condition interaction significantly contributing above and beyond all other variables in the model, $B=-2.31$, Wald $(2)=4.022, p=.045$. Follow-up Pearson chi-square analyses by age group revealed that there was no significant difference in leakage rates between the Control (24\%) and Putative Confession (21\%) conditions for 11- and 12-year-olds. However, 9- and 10-year-olds in the Putative Confession condition (47\%) were significantly more likely to leak details of the forbidden game during the recall question phase compared with the Control condition (9\%), $\chi^{2}(1,48)=8.83, p=.003$, Cramer's $V=.429$.

\section{Yes/No Played Game questions}

We examined whether there were differences in children's reporting of Played Game details between concealers in the Break condition $(n=84)$ and children in the No-Break condition $(n=164)$ in response to yes/no recognition questions. We also assessed whether the coaching of 4 details to conceal and 4 details to report in the Break condition accentuated any potential differences (Fig. 3 ). A 2 (Transgression Condition: Break or No-Break) $\times 2$ (Coaching: coached or not coached) $\times 2$ (Age Group: 9- and 10-year-olds or 11- and 12-year-olds) $\times 2$ (Instruction Condition: Putative Confession or Control) repeated-measures ANOVA was performed with transgression condition, age group, and instruction condition as between-participant factors, coaching as a repeated within-participant factor, and endorsement of Played Game details (means out of 4) as the dependent variable. Although no

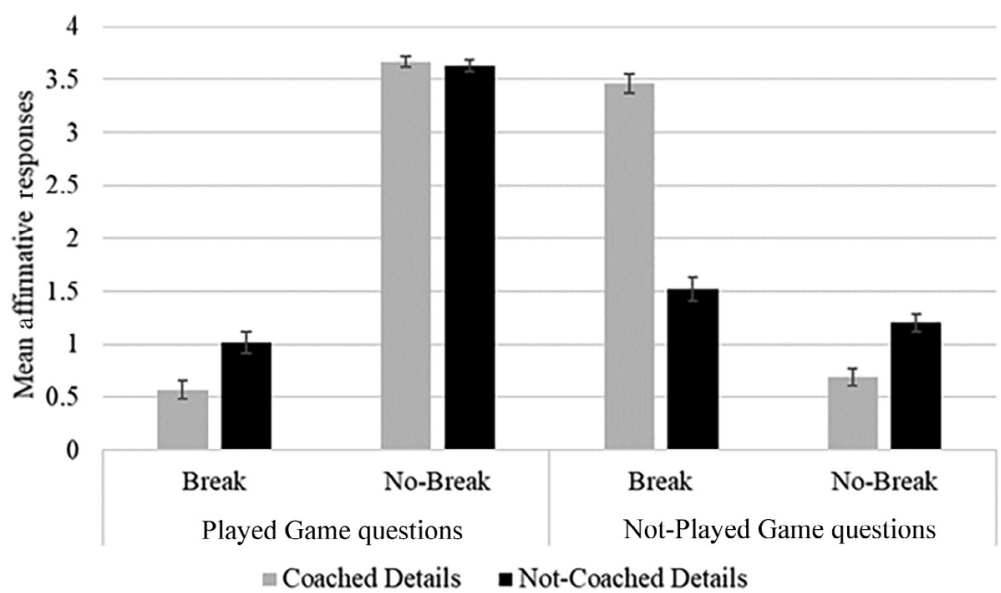

Fig. 3. Mean numbers of affirmative responses for Played Game questions and Not-Played Game questions by transgression condition and coaching. Note that children in the No-Break condition did not receive any coaching. "Coached Details" refers to those details corresponding to the details about which children in the Break condition were coached. 
coaching occurred in the No-Break condition, the same items that were coached in the Break condition were used as a baseline comparison from the No-Break condition.

Significant main effects of coaching, $F(1,240)=8.62, p=.004, \eta_{\mathrm{p}}^{2}=.035$, and transgression condition, $F(1,240)=1043.65, p<.001, \eta_{\mathrm{p}}^{2}=.814$, were qualified by a significant Coaching $\times$ Transgression Condition interaction, $F(1,240)=12.52, p<.00, \eta_{\mathrm{p}}^{2}=.050$. Separate follow-up repeated-measures ANOVAs were performed for the Break and No-Break conditions. For the Break condition, concealers were significantly less likely to affirm Game Played details that they were coached to conceal $(M=0.57$, $S D=1.02,14 \%$ ) compared with Game Played details that they were not coached to conceal $(M=1.02, S D=1.07,25 \%), F(1,79)=11.62, p=.001, \eta_{\mathrm{p}}^{2}=.128$. For the No-Break condition, no significant differences were found in the rate of affirming Game Played details based on whether they were items that were coached in the Break condition $(M=3.67, S D=0.58,92 \%)$ or not coached in the Break condition $(M=3.63, S D=0.59,91 \%), F(1,160)=0.344, p=.558, \eta_{\mathrm{p}}^{2}=.002$, confirming that any potential coaching effects were not due to the types of items that were coached or not coached. No other significant main effects or interactions were found.

\section{Yes/No Not-Played Game questions}

Next, we examined whether concealers in the Break condition $(n=84)$ were more likely to endorse details about the game they did not play compared with children in the No-Break condition $(n=164)$. In addition, we assessed whether coaching accentuated any potential differences (Fig. 3). A 2 (Transgression Condition: Break or No-Break) $\times 2$ (Coaching: coached or not coached) $\times 2$ (Age Group: 9and 10-year-olds or 11- and 12-year-olds) $\times 2$ (Instruction Condition: Putative Confession or Control) repeated-measures ANOVA was performed with transgression condition, age group, and instruction condition as between-participant factors, coaching as the repeated measure, and affirmative responses to Not-Played Game questions (means out of 4 ) as the dependent measure. Again, although no coaching occurred in the No-Break condition, the same items that were coached in the Break condition were used as a baseline comparison for the No-Break condition.

Significant main effects of coaching, $F(1,240)=72.30, p<.001, \eta_{\mathrm{p}}^{2}=.231$, and transgression condition, $F(1,240)=219.77, p<.001, \eta_{\mathrm{p}}^{2}=.478$, were qualified by a Coaching $\times$ Transgression Condition interaction, $F(1,240)=205.57, p<.001, \eta_{\mathrm{p}}^{2}=.461$. Separate follow-up repeated-measures ANOVAs were performed for the Break and No-Break conditions. In the Break condition, concealers were significantly more likely to endorse Not-Played Game details that they were coached to report $(M=3.46, S D=0.85,87 \%)$ compared with Not-Played Game details that they were not coached to report $(M=1.52, S D=1.21,38 \%), F(1,80)=164.16, p<.001, \eta_{\mathrm{p}}^{2}=.672$. In the No-Break condition, children were significantly less likely to endorse Not-Played Game details that children in the Break condition were coached to report $(M=.069, S D=0.81,17 \%)$ compared with Not-Played Game details that children in the Break condition were not coached to report $(M=1.20$, $S D=1.02,30 \%), F(1,160)=29.56, p<.001, \eta_{\mathrm{p}}^{2}=.156$. This suggests that the coached items were less likely to be confused with true game details compared with noncoached items. No other significant main effects or interactions were found.

\section{Yes/No non-occurring game questions}

Finally, we examined whether there were any differences in false alarming to questions about items that did not occur in either game. A 2 (Transgression Condition: Break or No-Break) $\times 2$ (Age Group: 9- and 10-year-olds or 11- and 12-year-olds) $\times 2$ (Instruction Condition: Putative Confession or Control) univariate ANOVA was performed with transgression condition, age group, and instruction condition as the between-participant factors and affirmative responses to Non-occurring Game questions (means out of 4 ) as the dependent variable.

A significant main effect of transgression condition was found, $F(1,240)=19.02, p<.001, \eta_{\mathrm{p}}^{2}=.137$. Concealers in the Break condition were significantly more likely to affirm Non-occurring Game details $(M=0.88, S D=0.97,22 \%)$ compared with children in the No-Break condition $(M=0.27, S D=0.51,6 \%)$. No other main effects or interactions were significant. 


\section{Discussion}

The aim of the current investigation was to assess the potential influence of the putative confession and evidence presentation on 9- to 12-year-old maltreated and non-maltreated children's coached reports of a minor transgression. Children played a computer game with a stranger, and when the game appeared to crash they learned that they should not have played the game and were coached to both conceal details of the game they played (omission coaching) and falsify details of the game they had not played (commission coaching). Only 13\% of the younger children (9- and 10-yearolds) revealed breakage when questioned compared with $48 \%$ of the 11 - and 12 -year-olds. In other words, nearly $90 \%$ of the younger children kept the breakage a secret, and about half of the older children did so.

The putative confession significantly increased the disclosure rate among the younger children (from 13\% to 63\%) but did not significantly influence the older children (from $48 \%$ to $63 \%$ ). Among children who failed to disclose during recall, the putative confession increased the likelihood that the younger children leaked details of the game in their recall (from 9\% to 47\%). Presentation of evidence elicited new disclosures of breakage from nearly two thirds of the children (63\%), and it was equally effective among age groups and interview conditions. Maltreated children responded similarly to the manipulations as non-maltreated children. No child falsely disclosed breakage.

Both omission coaching and commission coaching were effective in enabling concealers to make their reports appear to be honest both in recall and in response to the yes/no questions. Coached children concealed and denied details of the game they played, endorsed details of the game they failed to play, and showed some inclination to endorse noncoached details.

\section{Age effects}

The developmental increase in truth-telling regarding transgressions is consistent with previous experimental studies examining children during late childhood into adolescence (Evans \& Lee, 2010, 2011; Heyman, Loke, \& Lee, 2016; Lavoie, Yachison, Crossman, \& Talwar, 2017; McWilliams, Stolzenberg, Williams, \& Lyon, n.d.; Pipe \& Wilson, 1994) and extends these findings to commission coaching in which children are coached to falsify details to deceive the questioner. This increased honesty has been suggested to be related to an increase in children's moral development and the importance placed on truth-telling with age (e.g., Bussey, 1992, 1999). In addition, older children may fear the consequences of truth-telling less than younger children.

An important caveat, however, is that this age pattern might not apply to children's disclosures of transgressions implicating those close to them, including parents. Gordon, Lyon, and Lee (2014) found that $97 \%$ of 10 - to 12 -year-olds failed to disclose that their parent had broken a toy in recall (after promising not to tell), and the oldest children were less likely to disclose than the younger children. Familial relations may radically alter the dynamics of children's decision making about disclosing wrongdoing.

\section{The putative confession}

The effect of the putative confession on the younger children is consistent with a series of studies demonstrating that the putative confession elicits recall disclosures of transgressions among both maltreated and non-maltreated children from 4 to 9 years of age (Lyon et al., 2014; McWilliams, Stolzenberg, Williams, \& Lyon, n.d.; Quas, Stolzenberg, \& Lyon, 2018; Rush, Stolzenberg, Quas, \& Lyon, 2017; Stolzenberg, McWilliams, \& Lyon, 2017). This study extends upward the age for which the putative confession is effective and also demonstrates its efficacy in the face of commission coaching. The fact that children in the No-Break condition receiving the putative confession never made a false report, even after being shown false evidence that the computer crashed, is consistent with prior research finding that the putative confession is not suggestive when combined with suggestive questions (Cleveland et al., 2018; Rush et al., 2017). The efficacy of the putative confession in eliciting recall disclosures across this age range and in both maltreated and non-maltreated children is particularly 
remarkable given recent evidence that a promise to tell the truth appears to be less effective in influencing preschool children's reports (Bender et al., 2018; Quas et al., 2018) and may need to be combined with more direct questioning (such as repeated recall requests or recognition questions) to elicit disclosure of transgressions from maltreated children (McWilliams, Stolzenberg, Williams, \& Lyon, n. d.).

The failure of the putative confession to elicit increased disclosures from 11- and 12-year-old children may be attributable to the older children's greater sophistication in interpreting the instruction. Older children are more aware of referential ambiguity (Beal \& Flavell, 1984) and, thus, may have seen through the ambiguity of "everything that happened," recognizing that the interviewer did not explicitly say that the confederate had disclosed the transgression. Furthermore, because the confederate engaged in commission coaching, older children may have assumed that when the confederate told the experimenter "everything," this entailed reciting the false report. Future studies are needed to assess whether older children are unmoved by the putative confession across the board or whether commission coaching specifically undermines its efficacy.

\section{Leakage}

An interesting question is why the putative confession increased leakage among the younger children. As noted in the Introduction, Leach and colleagues (2004) found that when children had promised to tell the truth or had discussed the morality of lying, their subsequent lies were better detected by adults. The authors were unable to identify any specific behavior that differentiated the groups of children, but they speculated that "increasing the salience of the moral implications of lying may have interfered with children's ability to regulate their expressive behavior" (p. 672).

Similarly, the putative confession may have interfered with children's ability to control their leakage of incriminating details. According to the cognitive load approach of lie detection (Blandón-Gitlin, Fenn, Masip, \& Yoo, 2014; Vrij \& Granhag, 2012; Walczyk, Harris, Duck, \& Mulay, 2014), lying is cognitively more demanding than truth-telling. Therefore, increasing the cognitive load of a respondent will be more detrimental to a liar than to a truth-teller, resulting in increased leakage. Alternatively, the putative confession's reference to "everything that happened" may have increased concealing children's uncertainty about the story they should report. To better understand the mechanism, future research could compare the effects of the putative confession to tasks that more generally increase cognitive load.

\section{Evidence presentation}

Presenting children with evidence of breakage was remarkably effective in eliciting disclosures from most of the children who had been keeping breakage a secret at the same time that it did not lead any children to false alarm. Importantly, we did not combine evidence presentation with highly suggestive questioning. The interview progressed from open-ended questions (including "what happened," "what happened next," and requests to "tell me more" about details) to yes/no questions about specific details. Similarly, with respect to the honesty promotion techniques, we began with the more indirect approach of the putative confession, followed by presenting physical evidence of the transgression. This approach provided children with the opportunity to disclose without the need for presenting evidence. Importantly, when evidence was presented, it was not coupled with highly suggestive questions but rather with the simple "what happened" query.

We conducted the interview immediately after the transgression in order to assess children's reluctance to disclose free of memory failure. However, to ensure that evidence presentation does not have adverse effects on children's reports, future research should assess its effects on children's reports after a delay when children may be less certain about what occurred and, thus, may be more susceptible to accept false evidence (cf. Kassin \& Kiechel, 1996, in which adult participants could be induced to confess they had inadvertently crashed a computer). 
Omission and commission coaching

Children who concealed breakage were quite good at concealing evidence of the fact that they had played the forbidden game. In recall, truthful children (in the No-Break condition) mentioned $83 \%$ of the game details, whereas concealers mentioned only $8 \%$. In recognition, truthful children affirmed more than $90 \%$ of the game details, whereas concealers affirmed only $14 \%$ of the details they had been coached to deny. Children were even better at falsifying information. Not surprisingly, none of the truthful children mentioned details of the game they had not played in recall, but concealers mentioned 38\%. In recognition, truthful children false alarmed to $17 \%$ of the details that had been used for coaching, whereas concealers affirmed nearly $90 \%$.

Coaching children to conceal details is analogous to directed forgetting tasks in which children are taught to forget word lists. Previous research has suggested that children struggle with directed forgetting (see Wilson \& Kipp, 1998, for a review), however, children in our study quite successfully concealed specific information. One possible explanation for this finding is that the stakes were higher in our paradigm compared with the tasks used in directed forgetting. Support for this argument comes from Aslan, Staudigl, Samenieh, and Bäuml (2010), who found that children as young as 6 years demonstrated adult-like directed forgetting if the researcher showed children a list of words and then became flustered, said she made a mistake, and asked them to forget the list. Of course, this research suggests that with added delays, details that children were coached to omit might also be forgotten.

\section{Conclusion}

The results add to a growing body of research that both demonstrates children's reluctance to disclose transgressions and identifies means by which interviewers can elicit disclosures without resorting to unnecessary direct and leading questioning. Of course, field testing is necessary, as is careful discussion of the ethics of different techniques, including the putative confession and evidence presentation. Furthermore, this study highlights the need for further work on truth induction techniques that are resistant to the influence of coaching and that are effective with older children.

\section{Acknowledgments}

Portions of this research were presented at the 2013 biennial meeting of the Society for Research in Child Development, Seattle, and at the 2017 workshop on Invention of Lying: Language, Logic, and Cognition, Leiden, Netherlands. We thank Bruce John, Tyler Vestal, Paul Curtis, Brook Eggleston, Robin Licht, Danielle Schnelby, Leah Mirels, and Michelle Tomkovicz for assisting in data collection and coding. A special thank you goes to Elizabeth Ahern for her consultation on this project. We are grateful for the support of the Presiding Judge of the Los Angeles County Juvenile Court, the Los Angeles County Department of Children's and Family Services, Los Angeles County Children's Law Center, and the Children's Services Division of Los Angeles County Counsel. Preparation of this article was supported in part by National Institute of Child Health and Human Development Grants HD047290 and HD087685 as well as by the Social Sciences and Humanities Research Council of Canada.

\section{Appendix A. Yes/No questions}

\begin{tabular}{lll}
\hline Yes/No question & Game & Items coached \\
\hline Did you see a bug on the computer game? & Ball game & Coached \\
Did you click the green button on the computer? & Ball game & Coached \\
Did you see balls rolling across the screen? & Ball game & Coached \\
Did birds fly across the screen? & Ball game & Coached
\end{tabular}


Appendix A. (continued)

\begin{tabular}{lll}
\hline Yes/No question & Game & Items coached \\
\hline Was there fire at the start of the game? & Ball game & \\
Were there golden wings on the computer? & Ball game & \\
Did you see the stairs in the game? & Ball game & \\
Were there puddles of water on the screen? & Ball game & \\
Did you see little people at the bottom of the screen? & Jewel game & Coached \\
Was music coming from the computer? & Jewel game & Coached \\
Did you click the computer mouse? & Jewel game & Coached \\
Were there blocks falling from the top of the screen? & Jewel game & Coached \\
Was there a timer on the screen? & Jewel game & \\
Were there clouds in the sky on the game? & Jewel game & \\
Was there grass in the game? & Jewel game & \\
Did you see jewels on the computer? & Jewel game & \\
Did the lights go out in the room? & Non-occurring & \\
Did you see a picture of an oven? & Non-occurring & \\
Did [confederate's name] shake your hand? & Non-occurring & \\
Was there a dog in the video game? & Non-occurring & \\
\hline
\end{tabular}

\section{References}

Ahern, E. C., Stolzenberg, S. N., McWilliams, K., \& Lyon, T. D. (2016). The effects of secret instructions and yes/no questions on maltreated and non-maltreated children's reports of a minor transgression. Behavioral Sciences E the Law, 34, $784-802$.

American Professional Society on the Abuse of Children (2012). Practice guidelines: Investigative interviewing in cases of alleged sexual abuse. Chicago: Author.

Anderson, J., Martin, J., Mullen, P., Romans, S., \& Herbison, P. (1993). Prevalence of childhood sexual abuse experiences in a community sample of women. Journal of the American Academy of Child E Adolescent Psychiatry, 32, 911-919.

Aslan, A., Staudigl, T., Samenieh, A., \& Bäuml, K. T. (2010). Directed forgetting in young children: Evidence for a production deficiency. Psychonomic Bulletin \& Review, 17, 784-789.

Beal, C. R., \& Flavell, J. H. (1984). Development of the ability to distinguish communicative intention and literal message meaning. Child Development, 55, 920-928.

Bender, J., O'Connor, A. M., \& Evans, A. D. (2018). Mirror, mirror on the wall: Increasing young children's honesty through inducing self-awareness. Journal of Experimental Child Psychology, 167, 414-422.

Ben-Shakhar, G., \& Elaad, E. (2003). The validity of psychophysiological detection of information with the Guilty Knowledge Test: A meta-analytic review. Journal of Applied Psychology, 88, 131-151.

Blandón-Gitlin, I., Fenn, E., Masip, J., \& Yoo, A. H. (2014). Cognitive-load approaches to detect deception: Searching for cognitive mechanisms. Trends in Cognitive Sciences, 18, 441-444.

Brennan, M. (1994). The battle for credibility: Themes in the cross-examination of child victim witnesses. International Journal for the Semiotics of Law, 3, 51-73.

Bussey, K. (1992). Lying and truthfulness: Children's definitions, standards, and evaluative reactions. Child Development, 63, 129-137.

Bussey, K. (1999). Children's categorization and evaluation of different types of lies and truths. Child Development, 70, 1339-1347.

Cleveland, K. C., Quas, J. A., \& Lyon, T. D. (2018). The effects of implicit encouragement and the putative confession on children's memory reports. Child Abuse \& Neglect, 80, 113-122.

Connell, C. S., \& Finnegan, M. J. (2010, May 1). Interviewing compliant adolescent victims. FBI Law Enforcement Bulletin. Retrieved from: https://leb.fbi.gov/articles/featured-articles/interviewing-compliant-adolescent-victims.

Evans, A. D., \& Lee, K. (2010). Promising to tell the truth makes 8- to 16-year-olds more honest. Behavioral Sciences E' the Law, 28, 801-811.

Evans, A. D., \& Lee, K. (2011). Verbal deception from late childhood to middle adolescence and its relation to executive functioning skills. Developmental Psychology, 47, 1108-1116.

Evans, A. D., \& Lee, K. (2013). Emergence of lying in very young children. Developmental Psychology, 49, 1958-1963.

Evans, A. D., Xu, F., \& Lee, K. (2011). When all signs point to you: Lies told in the face of evidence. Developmental Psychology, 47, 39-49.

Fogliati, R., \& Bussey, K. (2015). The effects of cross-examination on children's coached reports. Psychology, Public Policy, and Law, 21, 10-23.

Gervais, J., Tremblay, R. E., Desmarais-Gervais, L., \& Vitaro, F. (2000). Children's persistent lying, gender differences, and disruptive behaviours: A longitudinal perspective. International Journal of Behavioral Development, 24, $213-221$. 
Goodman, G. S., Quas, J. A., Bulkley, J., \& Shapiro, C. (1999). Innovations for child witnesses: A national survey. Psychology, Public Policy, and Law, 5, 255-281.

Gordon, H. M., Lyon, T. D., \& Lee, K. (2014). Social and cognitive factors associated with children's secret-keeping for a parent. Child Development, 85, 2374-2388.

Heyman, G. D., Loke, I. C., \& Lee, K. (2016). Children spontaneously police adults' transgressions. Journal of Experimental Child Psychology, 150, 155-164.

Kassin, S. M., \& Kiechel, K. L. (1996). The social psychology of false confessions: Compliance, internalization, and confabulation. Psychological Science, 7, 125-128.

Katz, C., Piller, S., Glucklich, T., \& Matty, D.E. "Stop waking the dead": Internet child sexual abuse and perspectives on its disclosure. Journal of Interpersonal Violence. in press, Advance online publication. doi:10.1177/0886260518796526.

Kloess, J. A., Beech, A. R., \& Harkins, L. (2014). Online child sexual exploitation: Prevalence, process, and offender characteristics. Trauma, Violence, \& Abuse, 15, 126-139.

Lamb, M. E., Orbach, Y., Hershkowitz, I., Esplin, P. W., \& Horowitz, D. (2007). Structured forensic interview protocols improve the quality and informativeness of investigative interviews with children: A review of research using the NICHD Investigative Interview Protocol. Child Abuse \& Neglect, 31, 1201-1231.

Lavoie, J., Yachison, S., Crossman, A., \& Talwar, V. (2017). Polite, instrumental, and dual liars: Relation to children's developing social skills and cognitive ability. International Journal of Behavioral Development, 4, 257-264.

Leach, A.-M., Talwar, V., Lee, K., Bala, N., \& Lindsay, R. C. L. (2004). "Intuitive” lie detection of children's deception by law enforcement officials and university students. Law and Human Behavior, 28, 661-685.

Lyon, T. D., \& Dorado, J. S. (2008). Truth induction in young maltreated children: The effects of oath-taking and reassurance on true and false disclosures. Child Abuse \& Neglect, 32, 738-748.

Lyon, T. D., Malloy, L. C., Quas, J. A., \& Talwar, V. A. (2008). Coaching, truth induction, and young maltreated children's false allegations and false denials. Child Development, 79, 914-929.

Lyon, T. D., Wandry, L., Ahern, E. C., Licht, R., Sim, M. P. Y., \& Quas, J. (2014). Eliciting maltreated and non-maltreated children's transgression disclosures: Narrative practice rapport building and a putative confession. Child Development, 85, $1756-1769$.

Lytle, N. E., Dickinson, J. J., \& Poole, D. A. (2019). Techniques for interviewing reluctant child witnesses. In J. J. Dickinson, N. Schreiber Compo, R. Carol, B. L. Schwartz, \& M. McCauley (Eds.), Evidence-based investigative interviewing: Applying cognitive principles (pp. 193-215). New York: Routledge.

National Children's Advocacy Center. (2013). Position paper on the introduction of evidence in forensic interviews of children. Huntsville, AL: Author. Retrieved from: http://www.nationalchildrensalliance.org/wp-content/uploads/2018/04/NCACposition-paper-introduction-evidence-fi-1.pdf.

McWilliams, K., Stolzenberg, S.N., Williams, S., \& Lyon, T.D. (in press). Increasing maltreated and nonmaltreated children's recall disclosures of a minor transgression: The effects of back-channel utterances, a promise to tell the truth and a post-recall putative confession. Child Abuse \& Neglect..

Pipe, M.-E., \& Wilson, J. C. (1994). Cues and secrets: Influences on children's event reports. Developmental Psychology, 30 , $515-525$.

Polak, A., \& Harris, P. L. (1999). Deception by young children following noncompliance. Developmental Psychology, 35, $561-568$.

Quas, J. A., Goodman, G. S., \& Jones, D. P. (2003). Predictors of attributions of self-blame and internalizing behavior problems in sexually abused children. Journal of Child Psychology and Psychiatry, 44, 723-736.

Quas, J. A., Stolzenberg, S. N., \& Lyon, T. D. (2018). The effects of promising to tell the truth, the putative confession, and recall and recognition questions on maltreated and non-maltreated children's disclosure of a minor transgression. Journal of Experimental Child Psychology, 166, 266-279.

Rush, E. B., Stolzenberg, S. N., Quas, J. A., \& Lyon, T. D. (2017). The effects of the putative confession and parent suggestion on children's disclosure of a minor transgression. Legal and Criminological Psychology, 22, 60-73.

State of Michigan Governor's Task Force on Child Abuse and Neglect and Department of Health and Human Services. (2015). Forensic Interviewing Protocol (4th ed.). Retrieved from: https://www.michigan.gov/documents/dhs/DHS-PUB-0779_ 211637_7.pdf.

Stolzenberg, S. N., McWilliams, K., \& Lyon, T. D. (2017). Ask versus tell: Potential confusion when child witnesses are questioned about conversations. Journal of Experimental Psychology: Applied, 23, 447-459.

Summit, R. C. (1983). The child sexual abuse accommodation syndrome. Child Abuse Er Neglect, 7, 177-193.

Talwar, V., Arruda, C., \& Yachison, S. (2015). The effects of punishment and appeals for honesty on children's truth-telling behavior. Journal of Experimental Child Psychology, 130, 209-217.

Talwar, V., Gordon, H. M., \& Lee, K. (2007). Lying in the elementary school years: Verbal deception and its relation to secondorder belief understanding. Developmental Psychology, 43, 804-810.

Talwar, V., \& Lee, K. (2002). Development of lying to conceal a transgression: Children's control of expressive behaviour during verbal deception. International Journal of Behavioral Development, 26, 436-444.

Talwar, V., \& Lee, K. (2008). Social and cognitive correlates of children's lying behavior. Child Development, 79, 866-881.

Talwar, V., \& Lee, K. (2011). A punitive environment fosters children's dishonesty: A natural experiment. Child Development, 82 , $1751-1758$.

Talwar, V., Yachison, S., Leduc, K., \& Nagar, P. M. (2018). Practice makes perfect? The impact of coaching and moral stories on children's lie-telling. International Journal of Behavioral Development, 42, 416-424.

Tye, M. C., Amato, S. L., Honts, C. R., Devitt, M. K., \& Peters, D. (1999). The willingness of children to lie and the assessment of credibility in an ecologically relevant laboratory setting. Applied Developmental Science, 3, 92-109.

Vrij, A., \& Granhag, P. A. (2012). Eliciting cues to deception and truth: What matters are the questions asked. Journal of Applied Research in Memory and Cognition, 1, 110-117.

Walczyk, J. J., Harris, L. L., Duck, T. K., \& Mulay, D. (2014). A social-cognitive framework for understanding serious lies: Activation-decision-construction-action theory. New Ideas in Psychology, 34, 22-36.

Williams, S., Leduc, K., Crossman, A., \& Talwar, V. (2017). Young deceivers: Executive functioning and antisocial lie-telling in preschool aged children. Infant and Child Development, 26, e1956. 
Williams, S., Moore, K., Crossman, A. M., \& Talwar, V. (2016). The role of executive functions and theory of mind in children's prosocial lie-telling. Journal of Experimental Child Psychology, 114, 256-266.

Wilson, A. E., Smith, M. D., \& Ross, H. S. (2003). The nature and effects of young children's lies. Social Development, 12, 21-45.

Wilson, S. P., \& Kipp, K. (1998). The development of efficient inhibition: Evidence from directed-forgetting tasks. Developmental Review, 18, 86-123. 